\title{
WHAT IS AT STAKE?
}

\section{Practices of linking actors, issues and scales in environmental politics}

by Linda Soneryd

\begin{abstract}
Efforts to include a broader set of actors, knowledges and values in environmental decision-making have been promoted as a key remedy to technocratic decisionmaking and environmental degradation, and as instrumental for better decisions and democratic empowerment. Yet, such inclusive efforts yield uncertain results and entail various theoretical and practical problems, not least when environmental problems are increasingly complex and transgress political-geographic boundaries. We therefore need to take a step back from the normative presupposition that public involvement will enhance environmental governance with a more agnostic approach to its outcomes in terms of legitimate actors and issues: How are alliances created between issues and actors in relation to specific problems? How are stakes recognized as legitimate and tied to specific groups of actors and scales? What is the relation between governments' inclusive approaches and visions of socio-technical progress and alternative sociotechnical imaginaries of the future? This paper will discuss the contributions in this special issue in relation to these questions. The examples brought up by the authors can all be seen as practices in which legitimate participants and stakes are made real and with various scaling effects and possible futures as a result.
\end{abstract}




\section{N}

NORDIC JOURNAL

of Science and Technology Studies

\section{Introduction}

Environmental legislation and environmental protection agencies have been established in Western democracies since the 1970's. Citizen and stakeholder involvement in environmental decision-making has been increasingly emphasised since the end of the 1980's and has been "seen as integral to sustainability since the inception of a global sustainable development agenda" (Boström et al 2015: 8). There are today numerous international political declarations of the importance of public involvement in environmental planning and decision-making. The Aarhus Convention (1998) states that citizens should be entitled to access to information, public participation in decision-making, and access to justice in environmental matters. Together with the Aarhus Convention, legislative requirements for public consultations in environmental impact assessments (EIA Directive 1985) provide tools designed to democratize environmental decision-making and broaden the knowledge base for decisions. Further examples are the Seveso II Directive (1997), the European Union White Paper on Governance (2001) and the European Water Framework Directive (2000).

The arguments put forward for public involvement are that it can be a means to enrich environmental decision-making with knowledges and values and be a key remedy to technocratic decision-making, lead to better decisions that mitigate environmental degradation and contribute to democratic legitimacy and empowerment. Yet, to accomplish this is a precarious process that entails various theoretical and practical problems, not least when environmental problems are increasingly complex and transgress political-geographic boundaries. Who are the concerned publics when it comes to global environmental problems, and what can be the forms for involvement when issues transgress the political-administrative boundaries of national or local governments?

We also know that efforts to involve publics many times are pursued by decision-makers without much concern to enrich the decisions according to public values or knowledges, but rather with the motive to legitimise already taken decisions, prevent conflict or with the mission to inform an 'ignorant' public and to increase trust.
But it is not only a question of good or bad faith; even when public involvement is motivated by substantive and normative rationales, government-led public engagement initiatives can, as an effect, support a consensus seeking, narrowly framed and depoliticised agenda and therefore exclude important environmental values and concerned publics. It is therefore highly welcome to bring together research that discusses government-led public engagement exercises and transnational achievements of environmental movement actors. The cases that the contributions of this special issue refer to open up for discussions about what is at stake in environmental decision-making and how the on-going practices of linking actors, issues and scales is fundamental for how we can evaluate the outcomes of participatory environmental governance. It is suggested here that participatory governance should not be evaluated against some abstract theoretical model of democracy, but rather from its productive features; what boundaries are negotiated, re-enforced or re-shaped and in what sense is the environment or environmental values considered in such boundary work? Are there new types of resistance and activism shaped in the context of participatory governance? What role will 'uninvited' publics play? How can environmental movement actors make a difference if they are not as well organized as some of the established environmental NGOs?

If we take a step back from the normative presupposition that public involvement will enhance environmental governance we might assume a more agnostic approach and ask: How are alliances created between issues and actors in relation to specific problems? How are stakes recognized as legitimate and tied to specific groups of actors and scales? What is the relation between governments' inclusive approaches and visions of socio-technical progress and alternative socio-technical imaginaries of the future? In this paper I will discuss these questions in relation to my own on-going research as well as in relation to the two other contributions to this special issue. Public engagement and the politics of the environment can be studied as practices in which legitimate participants and stakes are made real and with various scaling effects and possible futures as a result.

\section{Participatory governance and environmental decision-making}

The papers by Alan Irwin and Erlend Hermansen in this issue both bring up climate change but also a variety of other environmental issues: flooding scenarios and adaptation, global food security, rainforest depletion, biotechnology. These issues are (or can be made to be) interrelated in several complex ways and they have to various extents been subject to public engagement ranging from social movement activism to more top-down public engagement exercises.

Participatory governance is a standard in several policy areas, not least in the area of environmental politics and science, technology and innovation; but the rationale for involving publics or a wider range of stakeholders, as well as how such initiatives play out in practice will differ in different policy areas depending on the institutional architecture and the practices of performing participatory governance in different context and situations. We can take a few examples of how public involvement might mean very different things in different policy areas.

A first example can be found in relation to water management in the European Union in which participation is heavily promoted through the Water Framework Directive (WFD) (EU 2000, EC 2003, see also 


\section{$\$$}

NORDIC JOURNAL

of Science and Technology Studies

Benson 2014). The WFD has been termed "one of the most important and most ambitious pieces of legislation in the history of the European Union's (EU) environmental policy" (Bourblanc 2013: 1449). Since it is a framework directive there are also considerable degrees of freedom in how the member states implement the requirements in the WFD. The Framework Directive encourages stakeholder involvement on the basis of an explicitly instrumental rationale; stakeholder involvement is assumed to facilitate the implementation of the WFD in order to accomplish better water quality. Since the WFD also means that hydrological and organisational boundaries are redrawn according to the natural water boundaries between water systems, this opens up for new situations and possibilities to enact stakeholders differently.

Secondly, there are policy areas that, in contrast, have relied more on a rationale to increase trust and where we can find several public engagement initiatives that have relied on a sharp distinction between 'publics' and stakeholder groups or activists with already entrenched positions. This has been seen especially in relation to emerging technologies such as biotechnology (McNeil and Haran 2013, Reynolds 2013). The consensus conference has, for example, been used frequently for issues related to biotechnology and in particular GM foods (Seifert 2006). The consensus conference is an instrument for public deliberation that is based on selection criteria that aim to gather a broad cross-section of 'ordinary citizens' who do not have already formed positions on the subject for deliberation.

Thirdly, there are also many examples of consumer oriented approaches and appeals to individual consumers' free choice, paired with encouragement to make the 'right' choice for the environment. Thus, 'individualized responsibility' is a form of environmental governance that is widespread in the Western world and means that citizens are increasingly addressed as responsible consumers by a number of actors, such as governments, corporations, and the mass media (Soneryd and Uggla 2015, Middlemiss 2014). Climate change is a good example of this since there are numerous examples of consumer oriented climate change messages in campaigns and popular culture (Larsson 2012, Maniates 2001, Minkel and Stix 2006, Uggla 2008) as well as carbon calculating devices that draws on individualised views of carbon emitters (Paterson and Stripple 2010).

These three examples are all from the three recent decades. The water framework directive was adopted in 2000 and implementation in the member states of the $\mathrm{EU}$ is still on-going. Biotechnology and $\mathrm{GM}$ food has been highly debated in Europe and subject to several government-led public engagement initiatives from the 1990 and onwards. The issue of climate change has been subject to several awareness raising campaigns since 2006, but a heightened focus on consumer responsibility can be noted from the late 1980 .

What can these dispersed examples of environmental governance tell us? They are all examples of efforts to engage publics and stakeholders in environmental governance, but in very different ways. The nation state is not missing from any of these examples, but its role has been redefined. A transnational world increasingly understands democracy through an emphasis on dialogue and broad participation (Djelic and Sahlin-Andersson 2008). Broadly speaking, one could say that this tendency towards 'participatory governance' is characterised by ad-hoc organizing. At least in comparison to the strongly institutionalised ideas of clear roles and responsibilities in a representative democracy and stable territorial boundaries of the nation state, participatory governance seems to be open in terms of who is involved, with what kind of agency, and within what relevant spatial and temporal boundaries. This does not mean that it is totally open how public engagement or stakeholder involvement is organized. The character of the policy field, its specific traditions and history, formal prerequisites, organizational routines, available resources and so on, sets limits to how participatory governance is pursued. In addition, there are plenty of helping hands in the growing field of participatory governance that can guide bewildered planners and decision-makers; there are blueprints for good governance, examples of best practice as well as a variety of methods and techniques for engaging the 'public' or 'stakeholders', which have their specific prerequisites and format.

While the democratic implications of new forms for participation have been a subject for academic debates for some time, the construction of legitimate participants through the designs and devices for participatory procedures have only recently become subject to theoretical and empirical investigations. Many of the contributors to this research have borrowed their analytical sensibilities and methodologies from science and technology studies (STS) and they have explored how certain versions or imaginaries of publics are deployed in the administrative-government practices at the expense of others (Braun \& Schultz 2010, Felt \& Fochler 2010, Irwin 2001). The tension between inviting parts of the public while excluding others is echoed in several of these studies, although explicitly highlighted by Welsh and Wynne (2013) who, in their effort to bring together STS and social movement studies, discuss the paradox between governments' inclusive approaches and increased surveillance of publics.

Imaginaries that policy-makers use to frame publics can be powerful, but they are also context specific, intrinsically embedded in the history and practice of particular organizations. For example, the assumption of publics as non-existing entities, as lacking hermeneutic capacities, or as threats, have emerged in relation to particular times and contexts of scientific governance in the UK, as shown by Welsh and Wynne (2013). Welsh and Wynne argue that by bringing together the distinct fields of STS and social movement studies we can improve our understanding of the relation between science and publics. The papers in this issue on government-led top-down approaches to public engagement relating to climate change adaption and global food security (Irwin, this issue), and on the achievements of environmental movement actors in global climate change politics (Hermansen, this issue) can both be discussed in relation to the wider question of how STS and social 


\section{N}

NORDIC JOURNAL

of Science and Technology Studies

movement studies can be brought closer to each other. I suggest that one way to do this is by focusing on how agency and public engagement in environmental politics are shaped through processes of linking actors, issues and scales.

\section{Linking actors, issues and scales}

Public engagement in environmental politics can always be discussed as a question of scale, for instance what the appropriate scale could be for government-led public engagement initiatives that concerns global issues or how an environmental NGO in a small nation like Norway could contribute to big achievements in global climate politics. Depending on whether issues are framed as local, regional, national or global, different issues will be seen as being at stake. By ascribing problems specific spatial characteristics, actors implicitly advocate a certain way of dealing with the problem as well as who should be responsible for taking action and who the potential concerned publics could be. Ascription of spatial identity is a performative act: localizing or globalizing an issue imbues it with meaning and creates opportunities for political action as well as for public engagement (cf. Czarniawska and Joerges 1996: 21).

Climate change is one of the most successfully framed global issues today. Climate change is only potentially a global political issue, although there might be politics (i.e. administrative and organisational boundaries) created at local, regional, national and international levels. Issues that are 'globalised', i.e. framed as global as an outcome of a politics of problem-labelling, may be used more efficiently to exert moral pressure on governments to act, than issues that are not framed as global issues; the label global may also give environmental NGOs a "viable mandate for operating outside the countries in which their supporter base and fund-raising lay" (Yearley 2005:48). However, while the label global gives the impression that it concerns us all, it does not demonstrate that the issues might not concern us all equally, and that there are in fact crucial differences in terms of the responsibilities for and impact of climate change. These boundaries can always be re-negotiated.

In the 1960's and 1970's grassroots mobilisations around pollution were reinforcing the responsibilities of the state to take environmental considerations, resulting in legislative changes in many Western democracies at this time. The Nordic countries were sometimes forerunners. For example, in Denmark biology and architecture students hijacked a conference in Copenhagen in 1969 and displayed the effects of pollution and waste dumping in front of the participating scientists and politicians. After this event the environmental group NOAH was established and expanded rapidly through local groups all over Denmark. In 1971 NOAH was asked to advise the newly founded Ministry of Pollution on the drafting of a Law of the Environment that came to be boosted as one of the most far reaching in the world at the time. NOAH was not happy with this. They expressed critique against the adopted legislation, since they wanted a much tougher regulation (Jamison et al 1990). This happened in a political economy that was different from the world of the events described in the papers by Irwin and Hermansen, possibly a less decentred one (although this can also be debated).

Today, many established environmental organisations have become professionalised, developed regular contact with decision-makers and are deeply involved in ordinary politics. This is also the case in Denmark and especially in the context of the UN climate negotiations. In research on how environmental movement actors in Denmark change their strategies in relation to climate change, we see few examples of politicisation and expressions of alternative visions of the future. Instead there is a tendency among established environmental NGOs to stabilise their regularized contacts with decision-makers in the context of the UN negotiations (Soneryd and Wettergren 2015).

Related to the question of how spatial boundaries shape responsibilities in certain ways is how environmental values are balanced against ideas about technical innovation and economic development (Lidskog et al 2009: 115). This is also an important dimension discussed by Irwin (this issue); if government institutions do not have the capacity to see alternatives to "a particular vision of socio-technical progress", then what are the possibilities for an open-ended democratic dialogue with concerned citizens? As has been pointed by Andrew Stirling, it is ironic that the appreciation of openness and public engagement happens just at a time "when processes of corporate concentration, institutional harmonization, and economic globalization render the governance of science and technology ever more obscure and inaccessible" (Stirling 2008:263).

There are obviously important differences between the cases brought up in this issue and the relation to a globalised economy and political power. The decision-makers who deal with concerns such as global food security are more dispersed and governance structures more obscure because of transnational flows of both food products and food innovations, than for example the decision-makers who can decide over climate change adaptations in Kalundborg (Irwin, this issue).

The alliances that could be mobilised were not only dependent on how issues were linked to each other (for example the linking of concerns for climate change and rain forest depletion) but also about translating issues into scientific calculations (Hermansen, this issue). The case of the mobilisation for Norway's contribution to the United Nation's REDD (Reducing Emissions from Deforestation and forest Degradation) mechanism, was successful partly because the argument based on calculations that saving 
the rain forest would be one of the less expensive measures with the most effects globally. Several factors affected this decision, such as good timing with the high attention that climate change had during 2007, and the effective interlinkages between the climate change issue and rainforest depletion. The fact that the Norwegian population could be shown to be highly concerned about climate change in opinion surveys mattered too; linkages were made between a global issue, a national population, and cost-effectiveness.

\section{Concluding remarks}

How is it possible to gain agency in environmental policy in an increasingly transnational and decentred world? First, not all issues are equally de-centred. Particular policy areas are always context specific, intrinsically embedded in the history and practice of particular organizations, and some of these organisations (for instance nation states and its administrative bodies at national, regional and local levels) are relatively stable, more or less transparent and have more or less well-working forms for public consultations for some issues and decision-making procedures. But these government bodies are not acting as one single rational and unified entity with high capacity to uphold democratic values. At the same time as governments may invite publics to open-ended discussions about social choice, publics can at the same time be "increasingly treated as threats to social and economic order" (Welsh and Wynne 2013: 541). Connecting studies of government-led public engagement initiatives to studies of social movements is therefore of high relevance if we want to focus on the broader patters on transnational governance and issue-mobilisation among wider publics.

\section{References}

Benson, D., O. Fritsch et al. 2014. Evaluating participation in WFD river basin management in England and Wales: Processes, communities, outputs and outcomes. Land use policy, 38:213-222.

Boström, M., Å. C. Vifell, et al. 2015, forthcoming. Social Sustainability Requires Social Sustainability. Procedural Prerequisites for Reaching Substantive Goals. Nature and Culture, 10 (2).

Bourblanc, M., A. Crabbe et al. 2013. The marathon of the hare and the tortoise: implementing the EU Water Framework Directive. Journal of Environmental Planning and Management, 56(10): 1449-1467.

Braun, K. and S. Schultz. 2010. '...a certain amount of engineering involved': Constructing the public in participatory governance arrangements. Public Understanding of Science, 19(4): 403-419.

Czarniawska, B. and B. Joerges. 1996. Travel of idea. In B. Czarniawska and G. Sevón (eds.) Translating Organizational Change.
Alan Irwin brings up the relationship between public engagement with science and democracy and asks whether public engagement initiatives can be "seen as a distraction from the democratic process or instead as an enhancement or invigoration of it?" He concludes by making three points: how to connect local initiatives with global events, the possible futures created in the present, and the challenge of relating scientific governance to basic choices about what society to wish to live in. On the basis of the contributions in this special issue, I would like to make a few concluding points in relation to these broad questions.

Second, the creation of new alliances and combining knowledges and insights in new ways is intrinsic to social movements (Jamison 2010). An example of this is the emerging issue of 'climate justice' that connects issues of the responsibilities of the Global North and the rights of the Global South, organisations collaboration in new constellations such as global aid organisations and environmental movement organisations, and new networks arise around the issue of climate justice (Thörn et al 2015). The climate issue, as many other environmental issues, are often narrowed down to "a technical problem that needs to be solved through a particular regime of international climate governance" (Pepermans and Maeseele 2014: 221) that deprive the political nature of these issues in terms of being open to discussions and "conflicting viewpoints about the future direction of society" (Berglez and Olausson 2014:54). The emerging alliances formed around 'climate justice' might be a way to counteract such post-political tendencies.

pp13-48. de Gruyter.

Djelic, M-L. and K. Sahlin-Andersson. 2006. Transnational Governance: Institutional Dynamics of Regulation. In M.L. Djelic and K. Sahlin-Andersson (eds.) Transnational Governance: Institutional Dynamics of Regulation. Cambridge University Press.

European Commission. 2001. European Governance: A White Paper, Commission of the European Communities.

European Commission. 2003. Common Implementation Strategy for the Water Framework Directive (2000/60/EC). Guidance document no. 8. Public participation in relation to the Water Framework Directive. Office for Official Publications of the European Communities.

EU. 2000. Water Framework Directive. 2000/60/EEC.

Felt, U. and M. Fochler. 2010. Machineries for Making Publics: 
Inscribing and De-scribing Publics in Public engagement. Minerva 48(3): $219-238$.

Irwin, A. 2001. Constructing the Scientific Citizen: science and democracy in the biosciences. Public Understanding of Science 10(1):1-18.

Jamison, A. 2010. Climate change knowledge and social movement theory. WIREs Climate Change $1: 811-823$

Larsson, B. 2012. The cosmopolitanization of childhood: eco-knowledge in children's eco-edutainment books. Young, 20 (2), 1999-2218.

Lidskog, R., L. Soneryd and Y. Uggla. 2009. Transboundary Risk Governance, Earthscan.

Maniates, M. F., 2001. Individualization: plant a tree, buy a bike, save the world? Global Environmental Politics, 1 (3), 31-52.

McNeil, M. and J. Haran. 2013. Publics of Bioscience. Science as Culture 22(4): 433-451

Middlemiss, L. 2014. Individualised or participatory? Exploring late-modern identity and sustainable development. Environmental Politics, 23 (6), 929-946.

Minkel, J.R. and G. Stix. 2006. Policy leader of the year. Scientific American, 295 (6), 51.

Paterson, M. and J. Stripple. 2010. My space: governing individuals carbon emissions. Environment and Planning D: Society and Space, 28 (2), 341-362.

Seifert, F. 2006. Local steps in an international career: A Danishstyle consensus conference in Austria. Public Understanding of Science, 15(1), 73-88.

Soneryd, L. and Y. Uggla. 2015. Green governmentality and responsibilization: new forms of governance and responses to 'consumer responsibility', Environmental Politics,

Soneryd, L. and $\AA$. Wettergren. 2015. Klimatförändring och emotionshantering: Institutionalisering av miljörörelsen i Danmark. Slagmark Tidskrift for Idéhistorie, 71:163-176

Thörn, H., C. Cassegård et al. 2015, forthcoming. National consensus culture meets global climate justice: the cases of Denmark, Japan, and Sweden.

Uggla, Y., 2008. Strategies to create risk awareness and legitimacy: the Swedish climate campaign. Journal of Risk Research, 11 (6), 719-734.

Welsh, I. and B. Wynne. 2013. Science, Scientism and Imaginaries of Publics in the UK: Passive Objects, Incipient Threats, Science as Culture, 22(4): 540-566.

Yearley, Steven. 2005. Cultures of Environmentalism. Empirical Studies in Environmental Sociology, Palgrave Macmillan 